
\title{
25 Research Soure \\ Prevalence, Risk Factors and Prevention of Depression in the Adult Population in Mbarara District, Uganda
}

Kiconco Allen囚 ( $\nabla$ allenkiconco@gmail.com )

Bishop Stuart University

Waswa Bright Laban

Bishop Stuart University

Ssemakula Edward

Bishop Stuart University

Baikirize Moses

Bishop Stuart University

Talbert Muhwezi

Bishop Stuart University

\section{Research Article}

Keywords: Depression, depression symptoms, rural settings, prevention, strategies, Uganda

Posted Date: November 30th, 2021

DOI: https://doi.org/10.21203/rs.3.rs-1107439/v1

License: (9) This work is licensed under a Creative Commons Attribution 4.0 International License. Read Full License 


\section{Abstract}

Background. This study concerns the prevalence, risk factors and prevention of depression in the adult population in three sub-counties in Mbarara district. Depression is a common mental disorder which presents with a wide array of symptoms including loss of energy, poor sleep, poor eating habits, fatigue, irritability and social withdrawal. The main objective of the present study was to determine the prevalence and factors associated with depression and to identify measures that can be implemented to reduce risk factors of the disease among adults in Nyamitanga, Rugando and Rwanyamahembe sub-counties in Mbarara district.

Methods. A cross-sectional design was used to capture data from a study sample size of 383 participants who were involved in completion of screening tests for depression. Scores from a 7-item version of Hopkins Symptom Checklist for Depression were averaged and the probable depression determined for each participant using a cut-off of 1.75. Logistic regression analyses were used to examine associations between depression outcomes and socio-demographic, behavioural and medical history variables.

Results. The analyses revealed that the prevalence of depression among adults in the area stands at $27.7 \%$. Depression was significantly associated with discrimination $(A O R=2.33,95 \% \mathrm{Cl}=1.22-4.45, \mathrm{P}=$ $0.010)$, household size $(A O R=0.54,95 \% \mathrm{Cl}=0.32-0.93, P=0.026)$, level of education (primary education: $\mathrm{AOR}=0.36,95 \% \mathrm{Cl}=0.15-0.88, \mathrm{P}=0.024$; secondary education: $\mathrm{AOR}=0.30,95 \% \mathrm{Cl}=0.12-$ $0.76, \mathrm{P}=0.011$; tertiary education: $\mathrm{AOR}=0.37,95 \% \mathrm{Cl}=0.15-0.92, \mathrm{P}=0.032)$ and drug-abuse related problems $(A O R=4.44,95 \% \mathrm{Cl}=1.34-14.74, \mathrm{P}=0.015)$. Measures for reducing the development of depression (which were identified by study participants) include guidance and counselling, awareness campaigns and self-help projects, improved access to quality medical services as well as stress management and spiritual care services.

Conclusions. These findings show that depression prevalence in the study area, estimated at $27.7 \%$, is high and worrying. Previous studies carried out in Mbarara district and other parts of Uganda have also reported similarly high estimates. They also show that discrimination, household size, level of education and drug-abuse are important risk factors associated with the prevalence of depressive disorders. Strategies targeted at early interventions and ultimately depression prevention need urgent attention in order to reduce risk factors of the disease.

\section{Background}

Depression is a common mental disorder that is characterised by a persistent low mood or loss of interest in pleasurable activities (American Psychiatric Association, 2013; Ministry of Health, 2017). Persons suffering from this disorder report a wide array of symptoms including feelings of anxiety (such as internal anxiety, panic attacks) and decreased emotional involvement (such as inability to feel positive feelings, worthlessness, relationship instability) (American Psychiatric Association, 2013; WHO, 
2017; Whitton \& Whisman, 2010). Suicidal thoughts and attempts are also symptoms of depression (Jeon, 2011). Domestic murders have also been associated with depression ( $\mathrm{MoH}, 2017)$. Depression can lead to disturbed sleep or appetite, and poor concentration (WHO, 2017).

Globally, depression is a major cause of morbidity and disability. Its burden of disease ranks high in many countries and by the year 2030 it is expected to be the largest contributor to the disease burden in both developed and developing countries (WHO, 2017). Quantitatively, depression led to a global total of over 50 million Years Lived with Disability (YLD) in 2015 and is expected to be the second leading cause of world disability by 2030 (Vos et al., 2015; WHO, 2017).

Depression should not be overlooked given the increasing morbidity and disease burden. The mental disorder causes impairment in functional well-being, physical distress, reduction in quality of life and other health problems (American Psychiatric Association, 2013; Fiske et al., 2009; Clarke \& Currie, 2009). It can also cause impairment in a person's role at home, work relationships and social network (Lynch, 2008). As such, a better understanding of depression and its associated factors is needed to help people know more about this disease especially how it can be prevented and treated $(\mathrm{MoH}, 2017)$.

In Sub-Saharan Africa, depression is reportedly one of the most prevalent psychiatric disorders observed in the adult population (Ayano et al., 2018; Bernard et al., 2017). Prevalence refers to the number of people who, at a given time, are depressed. According to published records, the prevalence of depression can be as high as $61 \%$ as found for female caregivers in Uganda (Familiar et al., 2016). But Ovuga et al. (2005) found the prevalence of depression in two rural districts in parts of West Nile and Eastern Uganda to be $17.4 \%$. In rural South Africa, Peltzer et al. (2016) found that $48.7 \%$ of HIV patients receiving primary care suffered from a depressive disorder. Furthermore, considerable literature points to depression being associated with female gender, marital status, employment status, alcohol use, large family size, drug use and HIV status (Ashaba et al., 2017; Familiar et al., 2016; Kasoro et al., 2002). As noted by Greenberg et al. (2015) the large number of adults suffering from depression is a major public health concern.

In Mbarara district and other parts of Uganda, depression is a common disorder affecting a large number of adults (Atuhaire et al., 2021; Byaruhanga et al., 2008; Hatcher et al., 2012; Rukundo et al., 2013). Depression among adults is known to decrease quality of life and increase medical problems and mortality. Although this may be the case, detection of depression in the adult population has largely remained unrecognized, and even when recognized it is undertreated or treated inappropriately. One of the reasons for this state of affairs is the tendency to focus on physiological factors in the diagnosis of depression. In addition, many patients in rural areas are not aware of the early signs of depression and other psychiatric and medical disorders and diseases associated with this mental disorder.

Screening and early interventions in rural areas are thus urgently needed in order to reduce the consequences and sufferings associated with this disease. As such, this study aimed to determine the prevalence of depression and its associated factors among adults in rural south western Uganda in the sub-counties of Nyamitanga, Rugando and Rwanyamahembe. By identifying the predictors, targeted and focused interventions could be undertaken to support high risk groups (such as people with lower levels 
of education, those living in large households and those affected by discrimination) in future community mental health programs.

Depression affects more than 350 million people worldwide, with the majority being those residing in households afflicted by high levels of poverty (WHO, 2017). According to studies conducted in different parts of Uganda, depression contributes to mortality and negatively affects the overall well-being of many people (Kaida et al., 2014; Kinyanda et al., 2011; Ovuga et al., 2005). Depression has over the years become a common case among adults, and this trend may be attributed to difficult life events including bereavement, loss of job, loss of social support, cognitive impairment, and physical disabilities $(\mathrm{MoH}$, 2017).

The prevalence of depression in urban areas has received considerable attention (e.g. Kamau et al., 2012; Mutumba et al., 2015), but few researchers have focused on risk factors for depression among adults living in rural households. The vast majority of people with depression in rural settings do not receive mental health care (WHO, 2018). Thus, attaining a better understanding of the risk factors associated with depression can enhance efforts for early detection and treatment, and further reduce symptoms and increase quality of life (Heppner \& Fischer, 2014). With this background there was need to investigate the relationship between risk factors and depression in a rural agrarian setting. Three sub-counties, with a combined population of 76,472 inhabitants many of whom are socially and economically disadvantaged (UBOS, 2014) and had not screened for symptoms of depression, were chosen for the study. The present study was thus designed to provide information on the prevalence and associated factors of depression and to identify measures that can be implemented to reduce risk factors of the disease among adults living in rural households.

\section{Methods}

The study was a cross-sectional survey that employed exploratory and analytical data analysis. This design was deemed appropriate because it is flexible and can systematically capture the information necessary for determining the prevalence of depression and associated factors among adults in the study area.

The study was conducted in three sub-counties in Mbarara district, namely, Nyamitanga, Rugando and Rwanyamahembe. A large fraction of the population in these three sub-counties is socially and economically disadvantaged and lives in the less urbanised part of Mbarara district. The district is bordered by Ibanda district in the north, Ntungamo district in the west, Isingiro district in the south and Kiruhura district in the east. The district headquarters formerly at the newly created Mbarara City, the largest urban center in the sub-region, are located approximately 290 kilometres (180 miles) southwest of Kampala, Uganda's capital city and largest metropolitan area. Study participants were deemed eligible if they were 18 years and older, resided in the study area and wilfully accepted to give written consent. Those below 18 years and those who appeared too weak to participate in the study were excluded. 
The researchers used multi-stage sampling technique to select sub-counties. This technique was applied because the study involved different stages of sampling before selecting the actual study participants. In the first stage, cluster sampling was used to select parishes. In the second stage, simple random sampling, particularly lottery system, was used to select villages from each parish mainly because village leaders did not have comprehensive lists of people living in their communities. Villages in each parish were used as a sampling frame and households were randomly selected from each village. Participants were randomly selected and only eligible ones who provided consent were interviewed and the number of participants determined based on the size of a village.

A semi-structured questionnaire with both closed and open-ended questions in English and Runyankore was employed to obtain data on factors associated with depression and measures for reducing depression risks. Trained interviewers who spoke the same language as respondents were deployed to help with translating and administering the questionnaire. Section A consisted of participants' demographic information including their gender, age, marital status and level of education. Sections B, C and $D$ comprised various questions regarding medical history and behaviour of each participant and possible measures for reducing depression risks in the study area. A 7-item version of Hopkins Symptom Checklist for Depression (HSCL-D) was used to assess depression (adapted from Ashaba et al., 2018; Derogatis et al., 1974). The checklist enabled participants, a representative sample from the general population, to rate how often they have experienced different symptoms associated with depression in the last 7 days. Scores ranged from 1 "not at all" through 4 "very much" and were based on a Likert-type scale. Level of depressive symptoms was then calculated as the mean score for each participant, with mean scores exceeding 1.75 indicating probable depression.

\section{Data screening and statistical analyses}

The data collected was entered in Microsoft Excel and exported to Minitab (version 14) for analysis. Scores from a 7-item version of Hopkins Symptom Checklist for Depression (HSCL-D) were averaged and the probable depression determined for each participant using a cut-off of 1.75 (see also Ashaba et al., 2018; Derogatis et al., 1974). Caseness is dichotomous. It takes only two values, 1 if the score exceeds the cut-off and 0 otherwise. For objective 1 , the prevalence of depression was determined by calculating the percentage of participants who met caseness for depression. For objective 2, bivariate and multiple logistic regressions were used to investigate associations between depression outcomes and sociodemographic, behavioural and medical history variables. Variables with a p-value less than 0.05 in the bivariate analysis were included in the multivariate model to identify factors associated with depression after adjusting for potential confounders. Results from statistical tests were considered statistically significant if the $p$-value was less than 0.05 . Finally, for objective 3 , we analysed the measures for reducing depression risks by calculating the frequency and percentage of each measure mentioned by the participants.

\section{Data presentation, analysis and interpretation}




\section{Descriptive statistics}

A total of 383 adults aged 18 and above from the sub-counties of Nyamitanga, Rugando and Rwanyamahembe participated in the study. Out of 383 participants, 212 (55.4\%) were female and 171 (44.6\%) were male. The majority $229(60.4 \%)$ had attained secondary education and above while 24 (6.2\%) had never had formal education. Their mean age was 35.9 years, with the youngest aged 18 and the oldest 85 years. Households consisted of 5.5 members on average (range: 1-20). More details of the socio-demographic characteristics and behavioural and medical history of the participants are shown in Table 1.

\section{Prevalence of depression}

The frequencies of each symptom endorsed are listed in Table 2, with the most common being sadness and tension. Feeling hopeless about the future and feeling of worthlessness were the least experienced symptoms of depression (Table 2). These scores were obtained using a 7-item version of Hopkins Symptom Checklist for Depression. They were averaged for each participant and the probable depression determined using a cut-off of 1.75 . From this analysis, it was revealed that the prevalence of depression in the study sample stands at $27.7 \%$ (Figure 2).

\section{Factors associated with depression}

\section{Bivariate analyses}

At a bivariate level, logistic regression was used to determine the single factors associated with depression. The analysis revealed that problem alcohol use $(\mathrm{OR}=1.9,95 \% \mathrm{Cl}=1.16-3.13, \mathrm{P}=0.011)$, drug use $(\mathrm{OR}=4.92,95 \% \mathrm{Cl}=1.88-12.88, \mathrm{P}=0.001)$, discrimination $(\mathrm{OR}=3.34,95 \% \mathrm{Cl}=1.93-5.79, \mathrm{P}=$ $0.001)$, being HIV positive $(\mathrm{OR}=2.01,95 \% \mathrm{Cl}=1.13-3.6, \mathrm{P}=0.018)$ and taking medications routinely (OR $=2.14,95 \% \mathrm{Cl}=1.31-3.48, \mathrm{P}=0.002)$ are associated with a higher likelihood of getting depression. On the other hand, the analysis showed that having fewer members in a household $(\mathrm{OR}=0.56,95 \% \mathrm{Cl}=$ $0.35-0.9, P=0.017$ ), being educated (primary education: $\mathrm{OR}=0.44,95 \% \mathrm{Cl}=0.21-0.95, \mathrm{P}=0.036$; secondary education: $\mathrm{OR}=0.35,95 \% \mathrm{Cl}=0.16-0.75, \mathrm{P}=0.007$; tertiary education: $\mathrm{OR}=0.34,95 \% \mathrm{Cl}=$ $0.16-0.73, \mathrm{P}=0.006)$ and having family support $(\mathrm{OR}=0.47,95 \% \mathrm{Cl}=0.28-0.78, \mathrm{P}=0.004)$ are associated with a lower risk of depression (Table 3 ).

\section{Multivariate approach}

At a multivariate level, all factors that had a p-value less than 0.05 in the bivariate analysis were included in the model. From this analysis, the results reveal that participants who had had drug-abuse related problems were 4.4 times more likely to be depressed than those who had not had such problems (Table 3; 
$\mathrm{AOR}=4.44,95 \% \mathrm{Cl}=1.34-14.74, \mathrm{P}=0.015)$. In addition, participants who had experienced discrimination on account of their health status were 2.3 times more likely to be depressed $(A O R=2.33$, $95 \% \mathrm{Cl}=1.22-4.45, \mathrm{P}=0.010$ ), as compared to the participants who had not experienced discrimination. Participants who hailed from households with five or fewer members had $46 \%$ reduction in risk of being depressed $(A O R=0.54,95 \% \mathrm{Cl}=0.32-0.93, \mathrm{P}=0.026)$, those with primary education had $64 \%$ reduction in risk $(A O R=0.36,95 \% \mathrm{Cl}=0.15-0.88, \mathrm{P}=0.024)$, those with secondary education had $70 \%$ reduction in risk $(A O R=0.30,95 \% \mathrm{Cl}=0.12-0.76, \mathrm{P}=0.011)$ while those with tertiary education had $63 \%$ reduction in risk of suffering from depression $(A O R=0.37,95 \% \mathrm{Cl}=0.15-0.92, \mathrm{P}=0.032)$.

\section{Measures for reducing depression risks}

Using the questionnaire, I also sought views of study participants regarding measures that can be implemented to reduce depression risks among adults in the study area (Table 4).

Most of the participants (55.9\%) called for more guidance and counselling services which can be achieved by establishing counselling centres and employing professional counsellors, $43.9 \%$ suggested the need for awareness campaigns and self-help projects while $29.2 \%$ pointed out the need to improve access and quality of medical services (Table 4). Other measures suggested include stress management and spiritual care services which may include prayers, retreats and fellowships, as reported by $11.0 \%$ of the participants, socialisation and problem sharing (11.0\%), establishing specialised clinics and rehabilitation centres for people with depression (5.0\%), timely screening and adherence to medication $(4.2 \%)$, promoting nutritional management and physical exercise (3.7\%), treatment of depression patients with respect (3.1\%) and helping adults improve self-esteem and avoid negative influence through patient empowerment programs (2.9\%).

\section{Discussion}

\section{Prevalence of depression among adults}

The study found that the prevalence of depression is high and worrying, estimated at $27.7 \%$ in the area. This finding is comparable to that of Ashaba et al., (2018) who found that approximately one quarter of the sample i.e. $27.3 \%$ met caseness for depression using a 7 -item depression subscale even when the present study used a considerably larger sample size (i.e. 383 vs 154 participants). It is also similar to the nationwide overall prevalence of $29.3 \%$ reported for Uganda (Kinyanda et al., 2011). However, the estimated prevalence is higher than the estimate of $17.4 \%$ found in Bugiri and Adjumani (Ovuga et al., 2005) but lower than the $61 \%$ rate found for female caregivers in Uganda (Familiar et al., 2016) and the 48.7\% estimate found for women during the prenatal period in rural South Africa (Peltzer et al., 2016). 
Nonetheless, the prevalence estimate found in this study lies within the estimated range for sub-Saharan Africa which stands between 9\% and 32\% (Ayano et al., 2018; Bernard et al., 2017).

\section{Factors associated with depression among adults}

This study found that discrimination, household size, level of education and drug-abuse related problems are associated with depression.

The higher prevalence of depression among adults who had been affected by discrimination is consistent with previous studies in and outside Africa (Akena et al., 2010; Simbayi et al., 2007; Vrendenburg et al, 1986). This finding underscores the importance of socialisation in the economic and social stability of adults. This is because isolation and exclusion from social situations may affect one's desire for selfpreservation and thus contribute to the tendency to neglect self-care needs (Tyer-Viola et al., 2014). Discrimination can also intensify the poverty, stress and insecurity of people in many resource-limited settings, resulting in worsened mental health (Tsai et al., 2011).

The higher prevalence of depression among those living in larger households might be an indicator of economic hardship which tends to lead to frustration, dysfunctional family life and feeling of worthlessness. This finding however contradicts studies in Brazil, Ghana and the US where the prevalence of depression was found to decrease as family size increased (dos Santos et al., 2012; Joy and Hudes, 2010; Kyerematen, 2012). In these non-Ugandan studies, many people were reportedly living alone implying that larger families can serve as social-support networks. As such, this unexpected finding is a cause for worry since social-support is increasingly becoming a scarce resource and the traditional extended family is diminishing throughout much of Africa (Afolabi et al., 2008).

The higher prevalence of depression among those who had no formal education indicates that educational attainment may have a protective effect against depression. As argued by Chevalier and Feinstein (2006), education can impact health by making individuals more able to process information and thereafter more health conscious. Several authors have also suggested that education provides a route to accumulated wealth which can buffer the onset of depression (Cassano and Fava, 2002; Kawachi, 2006). Other authors have suggested that the increased risk of significant depressive symptoms among people with lower levels of education is a reflection of the high burden of psychological distress linked to poverty (Kitshoff et al., 2012; Kyser et al., 2011).

The finding in the present study that drug-abuse related problems are associated with depression is a serious cause for worry but not unique. Previous studies, especially from Latin America, have shown that majority of patients with substance use disorder tend to suffer from depression (Ferigolo et al., 2009; Pirraglia et al., 2005; Pradhan et al., 2012). The worry stems from the fact that even in Uganda drugabuse related problems are common especially among older males with less education and among students (Kruse et al., 2015; Nalugya-Sserunjogi et al., 2016). 


\section{Measures to reduce depression risks among adults in the study area}

Study participants suggested a range of different measures which can be incorporated into efforts to prevent the development of depression both locally and in other areas. The suggested measures include guidance and counselling, awareness campaigns and self-help projects, improved access and quality of medical services as well as stress management and spiritual care services (Table 4). While the frequency of mentioning these measures was generally low (only counselling and guidance exceeded $50 \%$ ), this does not mean they would not have considerable impact on depression. For example, studies have found that self-regulation and physical exercises are efficient in preventing the development of depression among adults (Harnois and Gabriel, 2000; Nazroo and Edwards, 1998; Strauman and Eddington, 2017). Moreover, regular physical activities help improve cognitive functions along with mental wellbeing and develop a sense of purpose in one's life. It is therefore inferred that these and other measures not mentioned by the study participants, for example adopting the model of using lay health counsellors for the implementation of depression treatment and prevention programs (Patel et al., 2010; Tan et al., 2014; Cuijpers et al., 2016), can help reduce depression risks in the general adult population.

\section{Conclusions}

The prevalence of depression in three sub-counties of Nyamitanga, Rugando and Rwanyamahembe in Mbarara district stands at $27.7 \%$. The results also indicate that discrimination, household size, level of education and drug-abuse related problems are important risk factors associated with the prevalence of depressive disorders in the area. Measures for reducing the development of depression levels among adults (which were identified by study participants) include guidance and counselling, awareness campaigns and self-help projects, improved access and quality of medical services as well as stress management and spiritual care services.

\section{Recommendations}

The generally high prevalence of depression in the area calls for urgent interventions by Government and other stakeholders and these should address problems of drug-abuse, discrimination, large households and lack of education. First, patients with drug-abuse related problems should be helped by intervening early in incipient depressive symptomatology and by supporting them to live healthy lifestyles. Second, people with depression should be included as a vulnerable and marginalized group requiring prioritized attention and engagement within education, employment, health, social protection and poverty reduction strategies and programmes. Finally, longitudinal studies are needed to continuously assess the levels of depression in the area and to test the effectiveness of measures (identified by study participants) for addressing this mental health challenge.

\section{Declarations}


Author contributions: KA conceived the study, collected data and undertook data analysis and interpretation while WBL, SE, BM and TM provided guidance and critical input throughout the study. All authors read and agreed to the final manuscript.

Competing interests: The authors have no competing interests to declare.

Availability of data and materials. The datasets used and analyzed during the current study are available from the corresponding author (SS) on reasonable request.

Funding. Not Applicable

Consent for publication. Not Applicable

Acknowledgments: Special thanks go to the study participants, who willingly gave their time during interviews and shared their unique insights.

Corresponding Author. Kiconco Allen

\section{References}

1. Afolabi, M., Abioye-Kuteyi, E., Fatoye, F., Bello, I., and Adewuya, A. (2008). Pattern of depression among patients in a Nigerian family practice population. South African Family Practice, 50(2), 6369.

2. Akena, D. H., Musisi, S., and Kinyanda, E. (2010). A comparison of the clinical features of depression in HIV-positive and HIV-negative patients in Uganda. Afr J Psychiatry, 13: 43-51.

3. American Psychiatric Association. (2013). American Psychiatric Association Diagnostic and Statistical Manual of Mental Disorders ( DSM-V). New York: American Psychiatric Association (APA).

4. Ashaba, S., Kakuhikire, B., Vořechovská, D., Perkins, J. M., Cooper-Vince, C. E., Maling, S., Bangsberg, D. R., and Tsai, A. C. (2018). Reliability, validity, and factor structure of the Hopkins symptom checklist-25: Population-based study of persons living with HIV in rural Uganda. AIDS and Behavior, 22: $1467-1474$.

5. Atuhaire, C., Rukundo, G. Z., Nambozi, G., Ngonzi, J., Atwine, D., Cumber, S. N., and Brennaman, L. (2021). Prevalence of postpartum depression and associated factors among women in Mbarara and Rwampara districts of south-western Uganda. BMC Pregnancy Childbirth, 21:503.

6. Ayano, G., Solomon, M. and Abraha, M. (2018) A systematic review and meta-analysis of epidemiology of depression in people living with HIV in east Africa. BMC Psychiatry, 18: 254.

7. Bernard, C., Dabis, F., and de Rekeneire, N. (2017). Prevalence and factors associated with depression in people living with HIV in sub-Saharan Africa: A systematic review and meta-analysis. PloS one. 12(8): 0181960.

8. Byaruhanga, E., Cantor-Graae, E., Maling, S., and Kabakyenga, J. (2008). Pioneering work in mental health outreaches in rural, southwestern Uganda. Intervention (Amstelveen, Netherlands), 6(2), 117- 
131.

9. Cassano, P., and Fava, M. (2002). Depression and public health: an overview. Journal of Psychosomatic Research, 53(4): 849-857.

10. Clarke, D. M. and Currie, K. C. (2009). Depression, anxiety and their relationship with chronic diseases: a review of the epidemiology, risk and treatment evidence. Med J Aust;; 190(7) (suppl):S54S60.

11. Cuijpers, P., Shields-Zeeman, L., Walters B. H. and Petrea, I. (2016). EU compass for action on mental health and well-being. Prevention of depression and promotion of resilience. A scientific paper.

12. Derogatis, L. R., Lipman, R. S., Rickels, K., Uhlenhuth, E. H., and Covi, L. (1974). The Hopkins Symptom Checklist (HSCL): A self-report symptom inventory. Behavioral science, 19(1): 1-15.

13. dos Santos, M. J., Kawamura, H. C. and Kassouf, A. L. (2012). Socioeconomic conditions and risk of mental depression: An empirical analysis for Brazilian citizens. Economics Research International, doi:10.1155/2012/278906

14. Familiar, I., Murray, S., Ruisenor-Escudero, H., Sikorskii, A., Nakasujja, N., Boivin, M. J., Opoka, R., and Bass, J. K. (2016). Socio-demographic correlates of depression and anxiety among female caregivers living with HIV in rural Uganda. AIDS Care, 28(12): 1541-1545.

15. Ferigolo, M., Stein, A. T., Fuchs, F. D., and Barros, H. M. T. (2009). Influence of depression and early adverse experiences on illicit drug dependence: a case control study. Rev Bras Psiquiatr. 31(2): 10613.

16. Fiske, A., Wetherell, J. L. and Gatz, M. (2009). Depression in older adults. Annual review of clinical psychology, 5: 363-389.

17. Greenberg, P. E., Fournier, A.-A., Sisitsky, T., Pike, C. T., Kessler, R. C. (2015). The economic burden of adults with major depressive disorder in the United States (2005 and 2010). J Clin Psychiatry. 76(2):155-62.

18. Harnois, G. and Gabriel, P. (2000). Mental health and work: Impact, issues and good practices. Geneva: World Health Organisation/International Labour Organisation.

19. Hatcher, A. M., Tsai, A. C., Kumbakumba, E., Dworkin, S. L., Hunt, P. W., Martin, J. N., et al. (2012). Sexual relationship power and depression among HIV-infected women in Rural Uganda. PloS one. 7(12):e49821.

20. Heppner and Fischer, (2014). Understanding men's psychological distress: contributions of problemsolving appraisal and masculine role conflict. Psychology of Men \& Masculinity, 5: 168-177.

21. Jeon, H. (2011). Depression and suicide. Journal of the Korean Medical Association; 54: 370 e5.

22. Joy, A. B. and Hudes, M. (2010). High risk of depression among low-income women raises awareness about treatment options. California Agriculture, 64(1): 22-25.

23. Kamau, J. W., Kuria, W., Mathai, M., Atwoli, L., and Kangethe, R. (2012). Psychiatric morbidity among HIV-infected children and adolescents in a resource-poor Kenyan urban community. AIDS Care, 24: 836-842. 
24. Kasoro, S., Sebudde, S., Kabagame-Rugamba, E., Ovuga, E. and Boardman, A. P. (2002) Mental illness in one district in Uganda. Int J Soc Psychiatry 48:29-37.

25. Kawachi, I. (2006). Do depression and anxiety mediate the link between educational attainment and CHD? Psychosom. Med. 68: 25-32.

26. Kinyanda, E., Woodburn, P., Tugumisirize, J., Kagugube, J., Ndyanabangi, S., and Patel, V. (2011). Poverty, life events and the risk for depression in Uganda. Soc Psychiatry Psychiatr Epidemiol. 46(1): $35-44$.

27. Kitshoff, C., Campbell, L., and Naidoo, S. (2012). The association between depression and adherence to antiretroviral therapy in HIV-positive patients, KwaZulu-Natal, South Africa. Afr Fam Pr. 54: 145150.

28. Kruse, G. R., Bangsberg, D. R., Hahn, J. A., Haberer, J. E., Hunt, P. W., Muzoora, C., Bennett, J. P., Martin, J. N. and Rigotti, N. A. (2014). Tobacco use among adults initiating treatment for HIV infection in rural Uganda. AIDS Behav. 18(7): 1381-1389.

29. Kyerematen, V. (2012). A Descriptive study of emotional well-being among women in Ghana. MSc thesis, Duke University, Durham.

30. Kyser, M., Buchacz, K., Bush, T., et al. (2011). Factors associated with non-adherence to antiretroviral therapy in the SUN study. AIDS Care, 2: 1-11.

31. Lynch, J. (2008). Gender differences in depression: The role played by paternal attitudes of male superiority and maternal modeling of gender-related limitations. Sex Roles, 38: 539-555.

32. MoH (2017). Ministry of health press statement on world health day 2017. Uganda government, Kampala.

33. Mutumba, M., Resnicow, K., Bauermeister, J. A., Harper, G. W., Musiime, V., Snow, R. C., et al. (2015). Development of a psychosocial distress measure for Ugandan adolescents living with HIV. AIDS and Behavior, 19: 380-392.

34. Nalugya-Sserunjogi, J., Rukundo, G. Z., Ovuga, E., Kiwuwa, S. M., Musisi, S. and Nakimuli-Mpungu, E. (2016). Prevalence and factors associated with depression symptoms among school-going adolescents in Central Uganda. Child Adolesc Psychiatry Ment Health, 10:39.

35. Nazroo, J. Y. and Edwards, A. (1998). Gender differences in the prevalence of depression: Artifact, alternative disorders, biology or roles? Sociology of Health \& IIIness, 20: 1-15.

36. Ovuga, E., Boardman, J., and Wasserman, D. (2005). The prevalence of depression in two districts of Uganda. Soc Psychiatry Psychiatr Epidemiol. 40(6): 439-45.

37. Patel, V., Weiss, H. A., Chowdhary, N., Naik, S., Pednekar, S., Chatterjee, S., . . Kirkwood, B. R. (2010). Effectiveness of an intervention led by lay health counsellors for depressive and anxiety disorders in primary care in Goa, India (MANAS): A cluster randomised controlled trial. The Lancet, 376(9758): 2086-2095.

38. Peltzer, K., Rodriguez, V. J. and Jones, D. (2016). Prevalence of prenatal depression and associated factors among HIV-positive women in primary care in Mpumalanga province, South Africa. SAHARAJ: Journal of Social Aspects of HIV/ AIDS. 13(1):60-67. 
39. Pirraglia, P. A., Bishop, D., Herman, D. S., Trisvan, E., Lopez, R. A., Torgersen, C. S., et al. (2005). Caregiver burden and depression among informal caregiver HIV-infected individuals. J Gen Intern Med. 20: 510-4.

40. Pradhan, S. N., Sharma, S. C., Shrestha, M. R., and Shrestha, S. (2012). A study of depression among patients of substance use disorder. Journal of Kathmandu Medical College, 1(2): 96-99.

41. Rukundo, Z. G., Musisi, S., and Nakasujja, N. (2013). Psychiatric morbidity among physically ill patients in a Ugandan Regional Referral Hospital. African Health Sciences, 13 (1): 87 - 93.

42. Simbayi, L. C., Kalichman. S., Strebel, A., Cloete, A., Henda, N., Mqeketo, A. (2007). Internalized stigma, discrimination, and depression among men and women living with HIV/AIDS in Cape Town, South Africa. Soc Sci Med. 64: 1823-1831.

43. Strauman, T. J. and Eddington, K. M. (2017). Treatment of depression from a self-regulation perspective: basic concepts and applied strategies in self-system therapy. Cognit Ther Res. 41(1): 115.

44. Tan, L.,Wang, M-J., Modini, M., Joyce, S., Mykletun, A., Christensen, H. and Harvey, S. B. (2014). Preventing the development of depression at work: a systematic review and meta-analysis of universal interventions in the workplace. BMC Medicine, 12:74.

45. Tsai, A. C., Bangsberg, D. R., Emenyonu, N., Senkungu, J. K., Martin, J. N. and Weiser, S. D. (2011). The social context of food insecurity among persons living with HIV/AIDS in rural Uganda. Soc Sci Med. 73: 1717-1724.

46. Tyer-Viola, L. A., Corless, I. B., Webel, A., et al. (2014). Predictors of medication adherence among HIVpositive women in North America. J Obstet Gynecol Neonatal Nurs. 43: 168-178.

47. UBOS. (2014). National population and housing census 2014. Kampala, Uganda.

48. Vos, T., Barber, R. M., Bell, B., Bertozzl-Villa, A., Blrukov, S., Bolliger, I., . . Murray, C. J. L. (2015). Global, regional, and national incidence, prevalence, and years lived with disability for 301 acute and chronic diseases and injuries in 188 countries, 1990-2013: A systematic analysis for the global burden of disease study 2013. The Lancet, 386 (9995), 743-800.

49. Vrendenburg, K., Krames, L. and Flett, G. (1986). Sex differences in the clinical expression of depression. Sex Roles, 14: 37-49.

50. Whitton, S. and Whisman, M. (2010). Relationship satisfaction instability and depression. Journal of Family Psychology; 24: 791e4.

51. WHO (2017). Depression and other common mental disorders: Global health estimates. Geneva.

52. WHO (2018). mhGAP operations manual: mental health Gap Action Programme (mhGAP). Geneva: World Health Organization.

\section{Tables}

Table 1: Summary of descriptive statistics of variables used in logistic regression analysis 


\begin{tabular}{|c|c|c|}
\hline Variable & Category & $\mathrm{n}(\%)$ \\
\hline Age (years) & Mean; median; range & $35.9 ; 32 ; 18-85$ \\
\hline \multirow[t]{2}{*}{ Gender } & Male & $171(44.6 \%)$ \\
\hline & Female & $212(55.4 \%)$ \\
\hline \multirow[t]{2}{*}{ Marital status } & Married & $257(68.0 \%)$ \\
\hline & Unmarried & $121(32.0 \%)$ \\
\hline Household size & Mean; median; range & $5.5 ; 5 ; 1-20$ \\
\hline \multirow[t]{2}{*}{ Employment status } & Employed & $136(35.8)$ \\
\hline & Self-employed/Unemployed & $380(64.2)$ \\
\hline \multirow[t]{3}{*}{ Level of education } & None & $38(10.0 \%)$ \\
\hline & Primary & $112(29.6 \%)$ \\
\hline & Secondary and above & $229(60.4 \%)$ \\
\hline \multirow[t]{2}{*}{ Smoking } & Yes & $30(7.8 \%)$ \\
\hline & No & $353(92.2 \%)$ \\
\hline \multirow[t]{2}{*}{ Problem alcohol use } & Yes & 92 (24.2\%) \\
\hline & No & $288(75.8 \%)$ \\
\hline \multirow[t]{2}{*}{ Drug use } & Yes & $19(5.0 \%)$ \\
\hline & No & $360(95.0 \%)$ \\
\hline \multirow[t]{2}{*}{ Family support } & Yes & $287(76.9 \%)$ \\
\hline & No & $86(23.1 \%)$ \\
\hline \multirow[t]{2}{*}{ Discrimination } & Yes & $66(17.6 \%)$ \\
\hline & No & $309(82.4 \%)$ \\
\hline \multirow[t]{2}{*}{ HIV status } & Negative & $299(83.5 \%)$ \\
\hline & Positive & $59(16.5 \%)$ \\
\hline \multirow[t]{2}{*}{ Diabetic } & Yes & $28(9.9 \%)$ \\
\hline & No & $254(90.1 \%)$ \\
\hline \multirow[t]{2}{*}{ Cancer status } & Diagnosed with cancer & $13(4.8 \%)$ \\
\hline & No cancer & $257(95.2 \%)$ \\
\hline
\end{tabular}




\begin{tabular}{|lll|}
\hline Taking medications & Yes & $99(25.9 \%)$ \\
\hline & No & $283(74.1 \%)$ \\
\hline
\end{tabular}

Table 2: Frequency of symptoms of depression endorsed by study participants $(n=383)$

\begin{tabular}{|lllll|}
\hline Symptom of depression & Not at all & Occasionally & Quite often & Very often \\
\hline Feeling sad & $123(32.1 \%)$ & $175(45.7 \%)$ & $68(17.8 \%)$ & $17(4.4 \%)$ \\
\hline Feeling hopeless about the future & $265(69.2 \%)$ & $83(21.7 \%)$ & $21(5.5 \%)$ & $13(3.4 \%)$ \\
\hline Feeling lonely & $249(65.0 \%)$ & $91(23.8 \%)$ & $27(7.0 \%)$ & $16(4.2 \%)$ \\
\hline Crying easily & $244(63.7 \%)$ & $99(25.8 \%)$ & $28(7.3 \%)$ & $12(3.1 \%)$ \\
\hline Feeling everything is an effort & $209(54.6 \%)$ & $116(30.3 \%)$ & $44(11.5 \%)$ & $14(3.7 \%)$ \\
\hline Feeling of worthlessness & $289(75.5 \%)$ & $57(14.9 \%)$ & $30(7.8 \%)$ & $7(1.8 \%)$ \\
\hline Feeling tense & $192(50.1)$ & $138(36.0 \%)$ & $36(9.4 \%)$ & $17(4.4 \%)$ \\
\hline
\end{tabular}

Table 3: Logistic regression of factors associated with depression among adults $(n=383)$. The outcome variable was probable depression which was a binary variable determined for each participant using a cut-off of 1.75 . 


\begin{tabular}{|c|c|c|c|c|}
\hline \multirow[b]{2}{*}{ Explanatory variable } & \multicolumn{2}{|l|}{ Bivariate analysis } & \multicolumn{2}{|c|}{ Multivariate analysis } \\
\hline & OR $(95 \% \mathrm{Cl})$ & $\begin{array}{l}\mathrm{P} \text { - } \\
\text { value }\end{array}$ & AOR $(95 \% \mathrm{Cl})$ & $\begin{array}{l}\mathrm{P}- \\
\text { value }\end{array}$ \\
\hline \multicolumn{5}{|l|}{ Age (years) } \\
\hline $18-24$ & Ref. & & & \\
\hline $25-34$ & $\begin{array}{l}0.85(0.45- \\
1.60)\end{array}$ & 0.611 & & \\
\hline $35-44$ & $\begin{array}{l}0.93(0.44- \\
1.96)\end{array}$ & 0.844 & & \\
\hline $45-54$ & $\begin{array}{l}0.89(0.42- \\
1.90)\end{array}$ & 0.767 & & \\
\hline$\geq 55$ & $\begin{array}{l}2.14(0.96- \\
4.77)\end{array}$ & 0.062 & & \\
\hline \multicolumn{5}{|l|}{ Gender } \\
\hline Male & $\begin{array}{l}0.93(0.59- \\
1.46)\end{array}$ & 0.761 & & \\
\hline Female & Ref. & & & \\
\hline \multicolumn{5}{|l|}{ Marital status } \\
\hline Married & $\begin{array}{l}0.68(0.42- \\
1.09)\end{array}$ & 0.109 & & \\
\hline Unmarried & Ref. & & & \\
\hline \multicolumn{5}{|l|}{ Household size } \\
\hline$\leq 5$ members & $0.56(0.35-0.9)$ & 0.017 & $\begin{array}{l}0.54(0.32- \\
0.93)\end{array}$ & 0.026 \\
\hline$>5$ members & Ref. & & & \\
\hline \multicolumn{5}{|l|}{ Employment status } \\
\hline Employed & $\begin{array}{l}0.98(0.61- \\
1.56)\end{array}$ & 0.927 & & \\
\hline Not employed & Ref. & & & \\
\hline \multicolumn{5}{|l|}{ Level of education } \\
\hline None & Ref. & & & \\
\hline Primary & $\begin{array}{l}0.44(0.21- \\
0.95)\end{array}$ & 0.036 & $\begin{array}{l}0.36(0.15- \\
0.88)\end{array}$ & 0.024 \\
\hline Secondary & $\begin{array}{l}0.35(0.16- \\
0.75)\end{array}$ & 0.007 & $\begin{array}{l}0.30(0.12- \\
0.76)\end{array}$ & 0.011 \\
\hline
\end{tabular}




\begin{tabular}{|c|c|c|c|c|}
\hline Tertiary & $\begin{array}{l}0.34(0.16- \\
0.73)\end{array}$ & 0.006 & $\begin{array}{l}0.37(0.15- \\
0.92)\end{array}$ & 0.032 \\
\hline \multicolumn{5}{|l|}{ Smoking } \\
\hline Yes & $2.14(1.0-4.57)$ & 0.050 & & \\
\hline No & Ref. & & & \\
\hline \multicolumn{5}{|c|}{ Problem alcohol use } \\
\hline Yes & $1.9(1.16-3.13)$ & 0.011 & $\begin{array}{l}1.22(0.64- \\
2.33)\end{array}$ & 0.544 \\
\hline No & Ref. & & & \\
\hline \multicolumn{5}{|l|}{ Drug use } \\
\hline Yes & $\begin{array}{l}4.92(1.88- \\
12.88)\end{array}$ & 0.001 & $\begin{array}{l}4.44(1.34- \\
14.74)\end{array}$ & 0.015 \\
\hline No & Ref. & & & \\
\hline \multicolumn{5}{|c|}{ Family support } \\
\hline Yes & $\begin{array}{l}0.47(0.28- \\
0.78)\end{array}$ & 0.004 & $\begin{array}{l}0.57(0.31- \\
1.06)\end{array}$ & 0.075 \\
\hline No & Ref. & & & \\
\hline \multicolumn{5}{|c|}{ Discrimination } \\
\hline Yes & $\begin{array}{l}3.34(1.93- \\
5.79)\end{array}$ & $<0.001$ & $\begin{array}{l}2.33(1.22- \\
4.45)\end{array}$ & 0.010 \\
\hline No & Ref. & & & \\
\hline \multicolumn{5}{|l|}{ HIV status } \\
\hline Positive & $2.01(1.13-3.6)$ & 0.018 & $0.97(0.4-2.36)$ & 0.949 \\
\hline Negative & Ref. & & & \\
\hline \multicolumn{5}{|l|}{ Diabetic } \\
\hline Yes & $\begin{array}{l}2.08(0.95- \\
4.56)\end{array}$ & 0.067 & & \\
\hline No & Ref. & & & \\
\hline \multicolumn{5}{|c|}{ Cancer status } \\
\hline With cancer & $\begin{array}{l}2.31(0.76- \\
7.05)\end{array}$ & 0.140 & & \\
\hline No cancer & Ref. & & & \\
\hline
\end{tabular}




\begin{tabular}{|lllll|}
\hline Taking medications & & & \\
Yes & $2.14(1.31-$ & 0.002 & $1.86(0.9-3.85)$ & 0.095 \\
& $3.48)$ & & & \\
\hline No & Ref. & & \\
\hline
\end{tabular}

\section{Table 4: Measures for reducing the risk of depression among adults in the study area}

\begin{tabular}{|lll|}
\hline Measures & Frequency & Percentage \\
\hline Guidance and counselling & 214 & 55.9 \\
\hline Awareness campaigns and self-help projects & 168 & 43.9 \\
\hline Improved access and quality of medical services & 112 & 29.2 \\
\hline Stress management and spiritual care services & 42 & 11.0 \\
\hline Socialisation and problem sharing & 42 & 11.0 \\
\hline Establishing specialised clinics and rehabilitation centres & 19 & 5.0 \\
\hline Timely screening and adherence to medication & 16 & 4.2 \\
\hline Nutritional management and physical exercise & 14 & 3.7 \\
\hline Treating patients with respect & 12 & 3.1 \\
\hline Improving self-esteem and avoiding negative influence & 11 & 2.9 \\
\hline Total & 383 & 100.0 \\
\hline
\end{tabular}

\section{Figures}




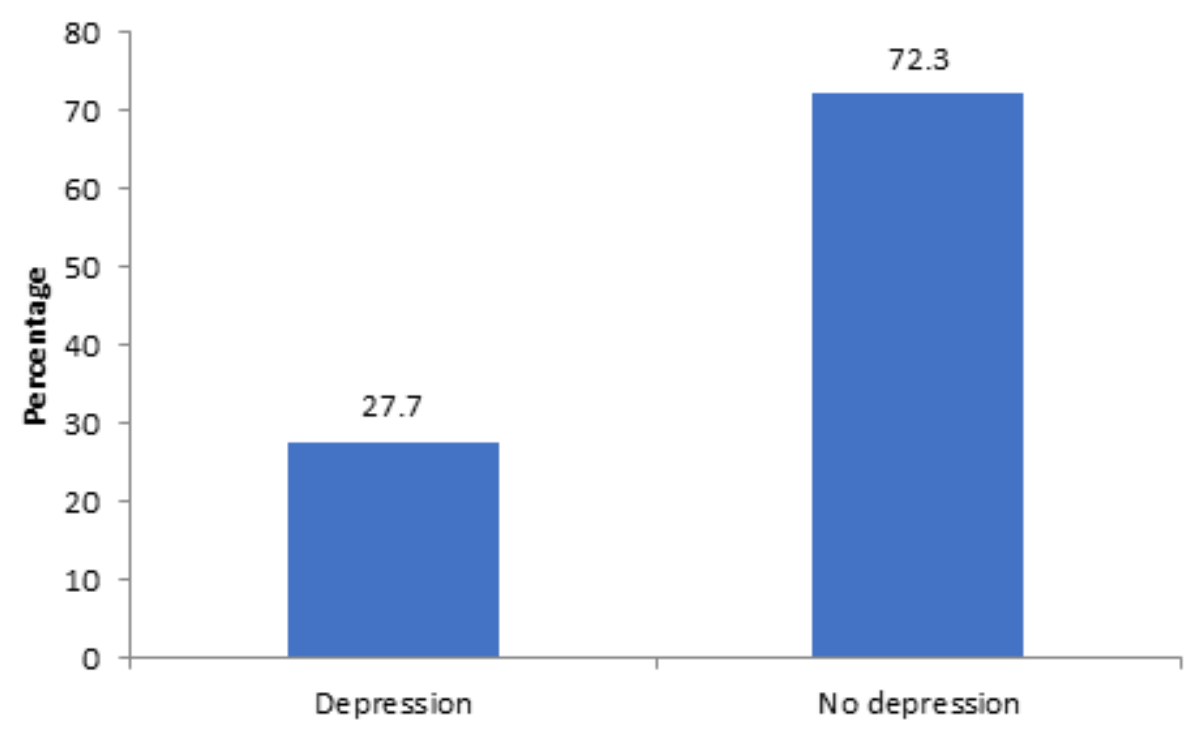

Figure 1

Prevalence of depression among adults in the study sample determined using scores from a 7-item version of Hopkins Symptom Checklist for Depression. Depression prevalence among adults was a binary variable determined for each participant using a cut-off of 1.75 . 